$\underline{\text { Original Article }}$

\title{
STUDIES ON BIOAVAILABILITY ENHANCEMENT OF CURCUMIN
}

\author{
N. R. KOTAGALE, P. B. CHARDE, A. HELONDE, K. R. GUPTA, M. J. UMEKAR, N. S. RAUT*
}

Department of Pharmaceutical Chemistry, Smt. Kishoritai Bhoyar College of Pharmacy, Kamptee, Nagpur, Maharashtra, India 441002

Email: rautneha123@gmail.com

Received: 10 Oct 2019, Revised and Accepted: 10 Dec 2019

ABSTRACT

Objective: The objective of the present work was to improve aqueous solubility and in vivo bioavailability of curcumin and structural analogues of curcumin such as potassium, calcium, magnesium salts and nitro derivative.

Methods: Structural analogues of curcumin were prepared by reaction of curcumin with potassium chloride, magnesium chloride hexahydrate and calcium chloride dihydrate in a suitable solvent. The nitro derivative synthesized by treating curcumin with sulphuric acid and nitric acid. The prepared analogues were evaluated for melting behavior, solubility, UV spectrophotometry, partition coefficient, moisture content, cellular uptake, FTIR analysis, antimicrobial activity and in vivo bioavailability in the rat.

Results: Chemical modification of curcumin increased the saturation solubility to $11.6,16.5,21.5,28.0 \mu \mathrm{g} / \mathrm{ml}$ in calcium salt, magnesium salt, potassium salt and nitro derivative respectively, against $8.6 \mu \mathrm{g} / \mathrm{ml}$ of curcumin. The analogues were chemically stable as curcumin analyzed by FTIR spectrophotometry. Increased cellular uptake, as well as enhanced antimicrobial activity, was demonstrated by modified curcumin analogues. Moreover, significant improvement in plasma levels was estimated with nitro derivative.

Conclusion: The present work recommends that nitration of curcumin improves aqueous solubility which may improve absorption and in vivo bioavailability.

Keywords: Curcumin, Structural analogues, Bioavailability, Antimicrobial activity

(C) 2020 The Authors. Published by Innovare Academic Sciences Pvt Ltd. This is an open-access article under the CC BY license (http://creativecommons.org/licenses/by/4.0/)

DOI: http://dx.doi.org/10.22159/ijpps.2020v12i2.36027. Journal homepage: https://innovareacademics.in/journals/index.php/ijpps

\section{INTRODUCTION}

Curcumin, a naturally occurring polyphenolic diferuloylmethane extracted from the rhizomes of plant Curcuma longa Linn. (Family: Zingiberaceae) has potential in the prevention and therapeutic interventions of several pathological conditions including respiratory diseases, inflammation, liver disorders and diabetic wounds. It prevents a variety of carcinogen-induced cancers in rodents by suppressing the mutagenic effects of carcinogens [1]. In addition, the hepato-and nephroprotective, thrombosis suppressing, myocardial infarction protective, hypoglycemic, and antirheumatic effects of curcumin are also reported [2-4]. Several animal and human studies have demonstrated the safety for curcumin at very high doses (12 g/d) [5-7] which makes it a potential compound for treatment and prevention of a wide variety of human diseases. In spite of its efficacy and safety, curcumin has not yet been approved as a therapeutic agent due to its low bioavailability presenting a significant pharmacological obstacle for clinical application. It is a hydrophobic compound with poor aqueous solubility and low absorption. It undergoes rapid metabolism and rapid systemic elimination further diminishing the bioavailability. The solubility of curcumin in water especially at acidic and physiological $\mathrm{pH}$ is extremely low (11 ng/ml). It undergoes rapidly hydrolysis under alkaline conditions and readily decomposed when exposed to bright light, high temperature or oxidative conditions [8]. Based on its poor aqueous solubility and permeability, curcumin can be classified as a BCS class IV molecule [9]. Effective pharmacokinetics is a surrogate for pharmacodynamics and is a determinant of therapeutic outcome. Although curcumin showed potential pharmacodynamics, it has poor pharmacokinetic characteristics. Many attempts have been made to increase solubility, absorption (permeability) and stability of curcumin in order to increase bioavailability.

Although many clinical trials for curcumin are currently ongoing [10], its clinical advancement of is hampered by its poor water solubility and short biological half-life and low bioavailability in both plasma and tissues [11-13]. The oral bioavailability of curcumin and synthetic structural analogues of curcumin is very low (only 1\% in rats) [14-16].
The motivation for building curcumin analogues is based upon its rapid metabolism and conjugation in the liver and its excretion through feces which limit the systemic bioavailability. In order to overcome these limitations, several approaches have been attempted including the combination of curcumin with adjuvants such as piperine [17] and the development of delivery vehicles consisting of liposomes nanoparticles a phospholipid complex [1820]. Several efforts for improving the systemic and tissue bioavailability of curcumin have largely been unsuccessful. The aim of the present work is to improve aqueous solubility and in vivo bioavailability of curcumin by using its structural analogues.

\section{MATERIALS AND METHODS}

Curcumin was received as gift sample from the Baidhyanath Pvt. Limited (Nagpur, India). Potassium hydroxide, calcium chloride dehydrate, magnesium chloride hexahydrate, and nitric acid, sulphuric acid were obtained from Merck Specialities Private Limited, Fisher Scientific and HiMedia Laboratories (Mumbai, India).

Preparation of structural analogues of curcumin

The structural analogues of curcumin were prepared by reaction of curcumin with potassium chloride, magnesium chloride hexahydrate and calcium chloride dihydrate in a suitable solvent (methanol, water). Salts were recrystallized and the resulting crystals were washed and dried [21]. The nitro derivative of curcumin synthesized, washed and dried [22].

\section{Preparation of potassium salt}

Aqueous $80 \mathrm{ml} \mathrm{KOH}$ was added to a solution of 5 g curcumin in $40 \mathrm{ml}$ chloroform. The mixture was sonicated for $4 \mathrm{~h}$. The organic layer was evaporated and aqueous layer was washed with a respective solvent. Salt was recrystallized with ethanol-water mixture and dried [23].

\section{Preparation of calcium salt}

A solution of calcium chloride dihydrate in $50 \mathrm{ml}$ of water was added to a solution of $20 \mathrm{~g}$ potassium salt in $250 \mathrm{ml}$ warm water. Stirring 
was continued for $3 \mathrm{~h}$, and then the crystals were filtered and washed with water. By using Potassium salt, calcium salts was prepared [23].

\section{Preparation of magnesium salt}

A solution of magnesium chloride hexahydrate in a $100 \mathrm{ml}$ of water was added with stirring to a solution of $20 \mathrm{~g}$ potassium salt in 250 $\mathrm{ml}$ warm water. Stirring was continued for $3 \mathrm{~h}$, and then the crystals were filtered and washed with water [23].

\section{Preparation of nitro derivative}

Curcumin was reacted with the mixture of sulphuric acid and nitric acid for $6 \mathrm{~h}$ in the reaction vessel. Then the mixture was filtered, washed and dried [23].

\section{Evaluation of structural analogues of curcumin}

\section{Melting point determination}

Melting point of curcumin and its structural analogues were determined in an electric melting point apparatus (Elico, India) by capillary method.

\section{UV spectrophotometric analysis}

Analysis of curcumin and its structural analogue in methanol was carried out using UV Spectrophotometer (Jasco, U. S. A.).

\section{Solubility study using the shake-flask method}

Saturated solutions of curcumin and its structural analogues were prepared by mixing an excess of solid solute in $10 \mathrm{ml}$ distilled water. Then these mixtures were agitated in mechanical shaker thermostated at $30{ }^{\circ} \mathrm{C} \pm 0.1^{\circ} \mathrm{C}$ for $24 \mathrm{~h}$. The filtered samples were diluted and analyzed by UV Spectrophotometry [24].

\section{Moisture content determination}

Approximately $1 \mathrm{~g}$ of the sample was dehydrated in hot air oven at $60{ }^{\circ} \mathrm{C}$ and reweighed at an interval of $10 \mathrm{~min}$ till the constant weight for three consecutive determinations and \% moisture loss was calculated.

\section{Partition coefficient determination}

The partition coefficient was determined using the shake-flask method. An excess amount of curcumin was shaken in an equal volume of octanol and water in a separating funnel. Then it was kept aside to separate the layers octanol and water. The separated layers were analyzed using uv-spectrophotometer at $271 \mathrm{~nm}$ wavelength.

\section{Cellular uptake determination}

The cellular uptake of curcumin and its salts/derivative were examined by UV spectrophotometry. A constant concentration (100 $\mu \mathrm{l})$ of curcumin and its salts were made and mix with an equal amount of stock solution of RBC $(10 \mathrm{ml}$ in $100 \mathrm{ml})$. The mixture was centrifuged at a fixed rpm at a $37^{\circ} \mathrm{C}$ for a $10 \mathrm{~min}$. Supernatant was collected and observed against the blank and saline solution [24]

\section{FTIR analysis}

Curcumin was dried in a hot air oven at $50^{\circ} \mathrm{C}$ for $1 \mathrm{~h}$. The samples were prepared by mixing it thoroughly with potassium bromide. This physical mixture was compressed under of $10 \mathrm{ton} / \mathrm{nm}^{2}$ and converted in a circular disc. This disc was then placed in a scanning slot of Fourier Transform Infra-red (FTIR) spectrophotometer (Shimadzu 1800) and scanned at range from 400 to $4000 \mathrm{~cm}^{-1}$. The spectrum was then compared with the spectrum of the reference standard.

\section{Antimicrobial assay}

Staphylococcus aureus and Escherichia coli (HiMedia Laboratories Mumbai, India). were used as the test organisms. Antimicrobial efficiency was determined by the Cup-Plate method. Sterile solutions of curcumin and its analogues were diluted at different concentration these solutions were poured into cups bored into sterile nutrient agar previously seeded with the test organisms, after allowing diffusion of the solution for $2 \mathrm{~h}$, the agar plates were incubated at $37^{\circ} \mathrm{C}$ for $24 \mathrm{~h}$. The zone of inhibition (ZOI) measured around each cup and was compared with that of control.

\section{In vivo bioavailability assessment}

Male Sprague rats weighing $250 \pm 20$ g were randomly divided into 5 groups and fasted for $10-12 \mathrm{~h}$ prior to experiments, although they were allowed free access to water. All the experimental protocol was carried out according to the guidelines of CPCSEA (853/AC/04/CPCSE). A feeding tube was inserted into the mouth of rat. The animals in the first groups were orally administered $1 \mathrm{ml}$ of 0.5 carboxymethyl cellulose (CMC) saline, an aqueous suspension containing curcumin at a dose of $100 \mathrm{mg} / \mathrm{kg}$, and those were remaining in the other groups were received potassium salt, calcium, magnesium, and nitro derivative respectively. Then $50 \mu \mathrm{l}$ of blood was collected from tail vein at a pre-determined interval for a $8 \mathrm{~h}$ and centrifuged at $12000 \mathrm{rpm}$ for $10 \mathrm{~min}$.

Plasma was mixed with ethyl acetate and extracted twice with it by vigorous shaking on a mechanical shaker for $10 \mathrm{~min}$. The upper organic layer was removed and placed in a cleaned centrifuge tube. The combined organic phase was then evaporated at room temperature and the residue was reconstituted with $100 \mu \mathrm{l}$ mobile phase. The $50 \mu \mathrm{l}$ of supernatant was analyzed by HPLC (Analytical). In HPLC mobile phase, THF ( $40 \%)$ and water containing $1.2 \%$ citric acid were used. The flow rate of $1 \mathrm{ml} / \mathrm{min}$ was used [24].

\section{RESULTS AND DISCUSSION}

Melting points for curcumin and its potassium, magnesium, calcium salts and nitro derivative were found to be in the range of $182-184^{\circ} \mathrm{C}$, $320-325{ }^{\circ} \mathrm{C}, 310-312{ }^{\circ} \mathrm{C}, 330-332{ }^{\circ} \mathrm{C}$ and $210-220^{\circ} \mathrm{C}$ respectively. Increased melting point of the salts might be a result of ionic nature of the salts. In addition, increased molecular weights of nitro derivative also resulted in increased melting temperature and hence require more energy for breaking of ionic bonds or ion-dipole or Vander wall interaction. The distinguishing and higher melting points confirmed the successful synthesis of curcumin derivative and salt.

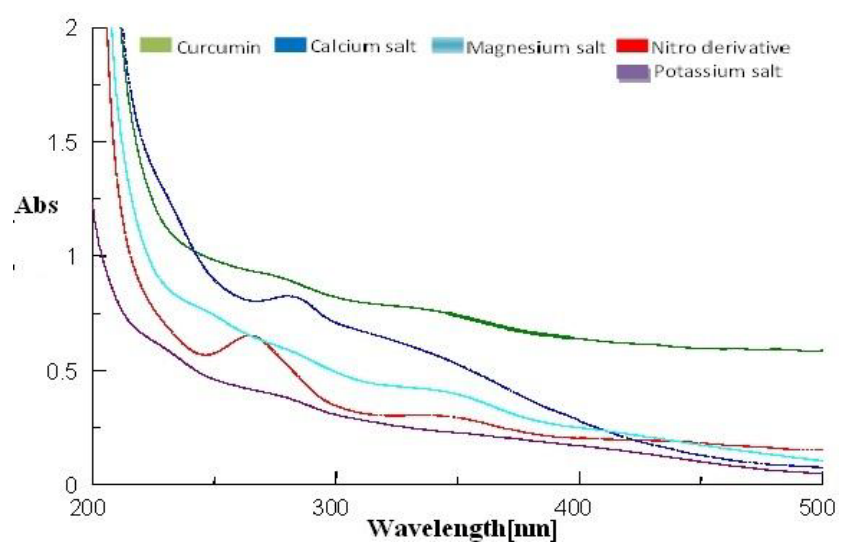

Fig. 1: Overlain of UV spectrum of curcumin and its potassium, calcium, magnesium salts and nitro derivative 
The UV spectrum was scanned for Curcumin at $\lambda_{\max } 271 \mathrm{~nm}$. As shown in fig. 1, UV spectra of curcumin and its analogues (salt and derivatives) exactly overlap to each other suggesting the intactness of the basic moiety of curcumin structure in its analogues. Moreover, the spectrum pattern in nitro derivative and calcium salt of curcumin showed sharp peak than other analogues. This was due to the group present in the nitro derivative of curcumin which shows the electronic transitions and responsible for giving sharp peak.

The solubility for curcumin and its calcium, magnesium, potassium salts, and nitro derivative were found to be $8.690 \pm 0.068,11.655 \pm 0.22$ $16.502 \pm 0.363$, and $21.551 \pm 0.162,28.050 \pm 0.202 \mu \mathrm{g} / \mathrm{ml}$ in water respectively. The solubility of calcium, magnesium, potassium salts and nitro derivative of curcumin observed increases in comparison with the curcumin. The enhanced solubility can be correlated with salt formation. Thus salt particles can get easily ionized, dispersed and immediately dissolved in presence of water. The maximum solubility was observed in nitro derivative compared with curcumin and its salts.

The \%moisture content for curcumin and its potassium, calcium, magnesium salts and nitro derivative were found to be $0.10,0.22$, $0.44,0.51$ and $0.14 \%$. The hygroscopic nature of curcumin analogues observed as increased compared with curcumin and maximum increment was found in magnesium salt of curcumin.

The partition coefficient (octanol/water) of curcumin, potassium salt, calcium salt, magnesium salt, and nitro derivative of curcumin were found to be $0.92085 \pm 0.121,0.46924 \pm 0.132,0.628095 \pm 0.121$, $0.84343 \pm 0.201$ and $0.29229 \pm 0.111$, respectively. From the above observations, with the decreasing partition coefficient the being lowest with nitro derivative. The partitioning of salt and derivative of curcumin were founds towards the higher level in the water phase because of its greater water solubility. Hence, the coefficients of salts and derivatives observed at lower range than that of curcumin. As higher water solubility required for the absorption of the drug through the gastrointestinal tract was shown by prepared curcumin analogues compared with curcumin.

The cellular uptake of curcumin, and its potassium, calcium, magnesium salts, and nitro derivative were found to be $86.86 \pm 0.755$, $99.05 \pm 0.055, \quad 98.13 \pm 0.107, \quad 97.32 \pm 0.154$ and $92.56 \pm 0.427 \%$ respectively. The highest cellular uptake was observed in potassium salt, $99.05 \pm 0.055 \%$ of curcumin was found to be taken up by RBCs from the solution [24].
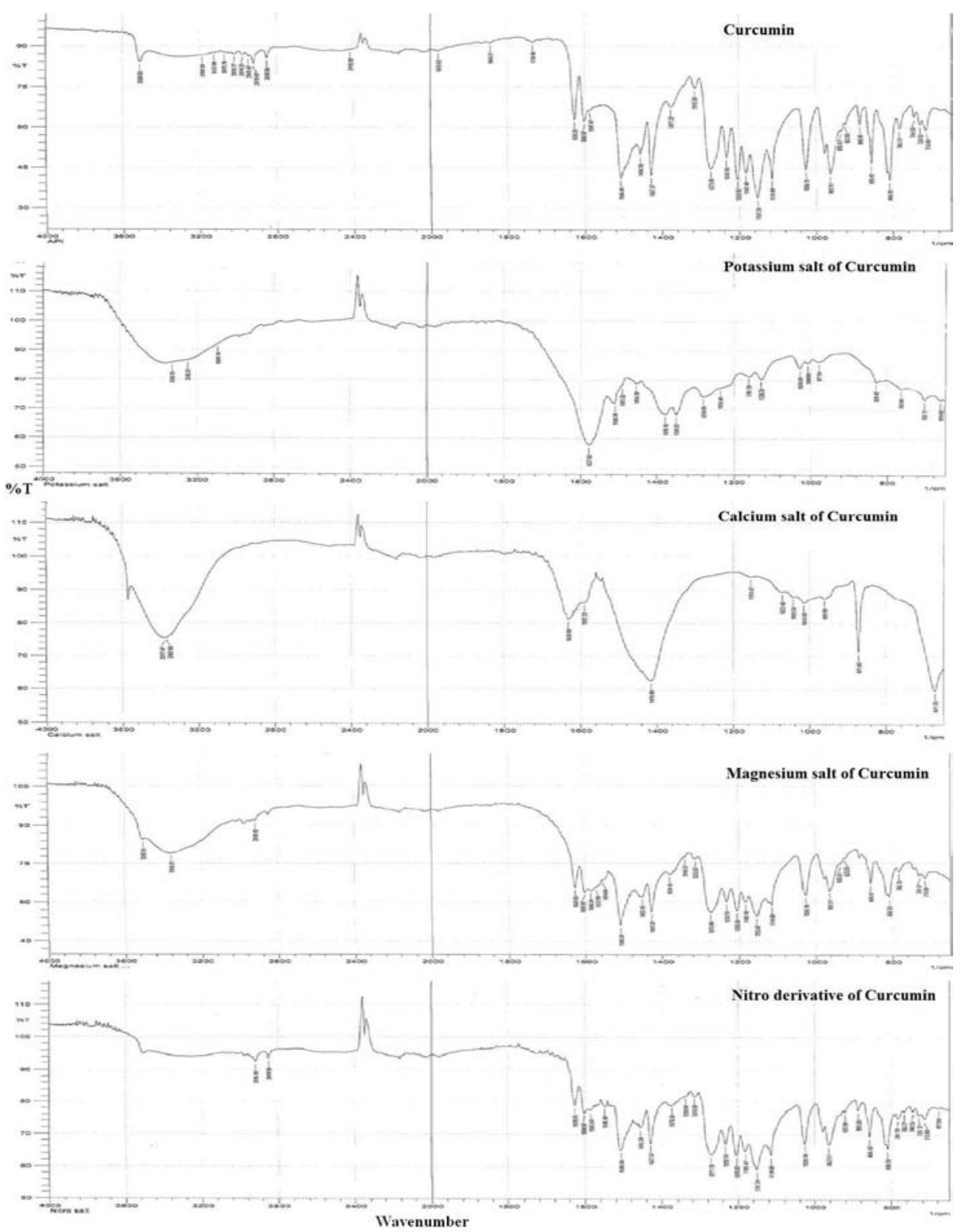

Fig. 2: FTIR spectrum of curcumin and its potassium, calcium, magnesium salts and nitro derivative 
Table 1: FTIR peaks of curcumin and its potassium, calcium, magnesium salts and nitro derivative

\begin{tabular}{lllll}
\hline $\begin{array}{l}\text { Functional } \\
\text { groups }\end{array}$ & \multicolumn{2}{l}{ Wavenumber $\left(\mathbf{c m}^{-\mathbf{1}}\right)$} & $\begin{array}{l}\text { Magnesium salt of } \\
\text { curcumin }\end{array}$ \\
\cline { 2 - 5 } & Curcumin & $\begin{array}{l}\text { Potassium salt of } \\
\text { curcumin }\end{array}$ & $\begin{array}{l}\text { Nitro derivative of } \\
\text { curcumin }\end{array}$ \\
\hline O-H stretching & 3508 & 3329 & 3377 & 3502 \\
C=O, C=C & 1626 & 1577 & 1629 & 1626 \\
Aromatic C=0 & 1601 & 1508 & 1591 & 1600 \\
Phenol, C-O & 1429 & 1454 & 1415 & 1427 \\
Enol & 1272 & 1278 & - & 1273 \\
NO & - & - & - & - \\
\hline
\end{tabular}

As shown in fig. 2 and table 1, the band at $3508 \mathrm{~cm}^{-1}$ indicates the presence of the hydroxyl group in the curcumin. The band of (phenol) alkanes (C-H) observed at 1350-1512 $\mathrm{cm}^{-1}$. FTIR spectrum of curcumin exhibited the absorption peaks 3508, 1626, 1601 and $1429,1272 \mathrm{~cm}^{-1}$ assigned to- $\mathrm{OH}, \mathrm{C}=\mathrm{O}$, phenol, enol, and $\mathrm{C}-\mathrm{O}-\mathrm{C}$ stretching respectively. The results were found to be concurrent with a reference spectrum of curcumin [25].

FTIR spectrum of calcium salt showed the absorption peaks 3377,1626 , 1591 and $1415 \mathrm{~cm}^{-1}$ associated with $\mathrm{O}-\mathrm{H}, \mathrm{C}=0$, aromatic $\mathrm{C}=0$, phenol, enol stretching respectively. The $\mathrm{O}-\mathrm{H}$ group shifting was observed in calcium salt from 3508 to $3377 \mathrm{~cm}^{-1}, \mathrm{C}=0$ group was shifted towards the lower wavenumber side from 1629 to $1626 \mathrm{~cm}^{-1}$, C-O shifted from 1429 to $1415 \mathrm{~cm}^{-1}$, enolic functional group is missing in calcium salt may be due to ionic nature and replacement of hydrogen ion by calcium cation. Moreover, retention of $\mathrm{O}-\mathrm{H}$ and $\mathrm{C}=\mathrm{O}$ groups indicated the presence of curcumin in its calcium salt in a stable form.

FTIR spectrum of potassium salt of curcumin illustrated the absorption bands at 3329, 1577, 1508 and $1454,1278 \mathrm{~cm}^{-1}$ allocated to $-\mathrm{OH}, \mathrm{C}=\mathrm{O}$, aromatic $=\mathrm{O}$, phenol, enol stretching respectively. The $\mathrm{O}-\mathrm{H}$ group shifting was observed in potassium salt from 3508 to
$3329 \mathrm{~cm}^{-1}, \mathrm{C}=0$ group was shifted towards the lower wavenumber from 1629 to $1577 \mathrm{~cm}^{-1}$, C-0 shifted from 1429 to $1454 \mathrm{~cm}^{-1}$, enolic group moved towards higher wavenumber from 1272 to $1278 \mathrm{~cm}^{-1}$. In these, all the functional groups of curcumin retained by its potassium salt suggested its chemical stability.

FTIR spectrum of the magnesium salt of curcumin showed the absorption peaks $3508,1626,1600$ and $1427,1273 \mathrm{~cm}^{-1}$ assigned to $-\mathrm{OH}, \mathrm{C}=\mathrm{O}$, aromatic $=\mathrm{O}$, phenol, enol stretching respectively. The $\mathrm{O}-\mathrm{H}$ group shifting was observed in magnesium salt from 3508 to 3502 $\mathrm{cm}^{-1}, \mathrm{C}-\mathrm{O}$ altered from 1429 to $1427 \mathrm{~cm}^{-1}$. In these, all the functional groups of curcumin retained by its magnesium salt suggested its chemical stability.

FTIR spectrum of nitro derivative exhibited the absorption bands 1628,1626 , and $1427,1271 \mathrm{~cm}^{-1}$ assigned to $-\mathrm{OH}, \mathrm{C}=0$, aromatic $=0$, phenol, enol stretching respectively. The C-O shifted from 1429 to $1427 \mathrm{~cm}^{-1}$, enolic group shifts towards lower side from 1272 to 1271 in nitro derivative. The functional groups of curcumin retained by its nitro derivative suggested its chemical stability. Additionally, the peak at $1548 \mathrm{~cm}^{-1}$ observed assisted with $\mathrm{N}-0$, suggested the formed derivative of curcumin was observed as chemically stable.

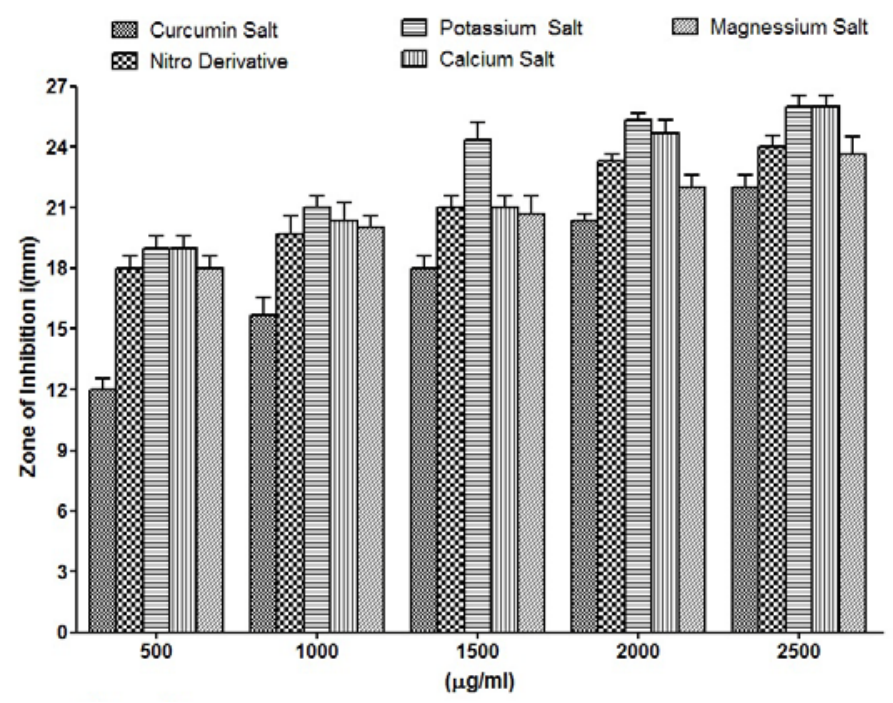

Fig. 3: Antibacterial activity of curcumin and its potassium, calcium, magnesium salts and nitro derivative, *values are expressed as mean+SEM

Table 2: Pharmacokinetic parameters calculated from the plasma curcumin profile following single oral administration of curcumin, its salts and derivative

\begin{tabular}{|c|c|c|c|c|}
\hline Compounds & C max ng/ml & $T \max (\min )$ & $t^{1} 1 / 2(\min )$ & AUC 0-t ng/mlmin \\
\hline Curcumin & 148.41 & 70 & 147.35 & 23673.6 \\
\hline Potassium salt of Curcumin & 84.91 & 60 & 56.87 & 52294.6 \\
\hline Calcium salt of Curcumin & 97.73 & 70 & 163.74 & 13822.1 \\
\hline Magnesium salt of Curcumin & 112.20 & 70 & 114.925 & 116805 \\
\hline Nitro derivative of Curcumin & 240.17 & 60 & 125.12 & 35971 \\
\hline
\end{tabular}

*Values are expressed as mean+SEM and $\mathrm{n}=12$ 


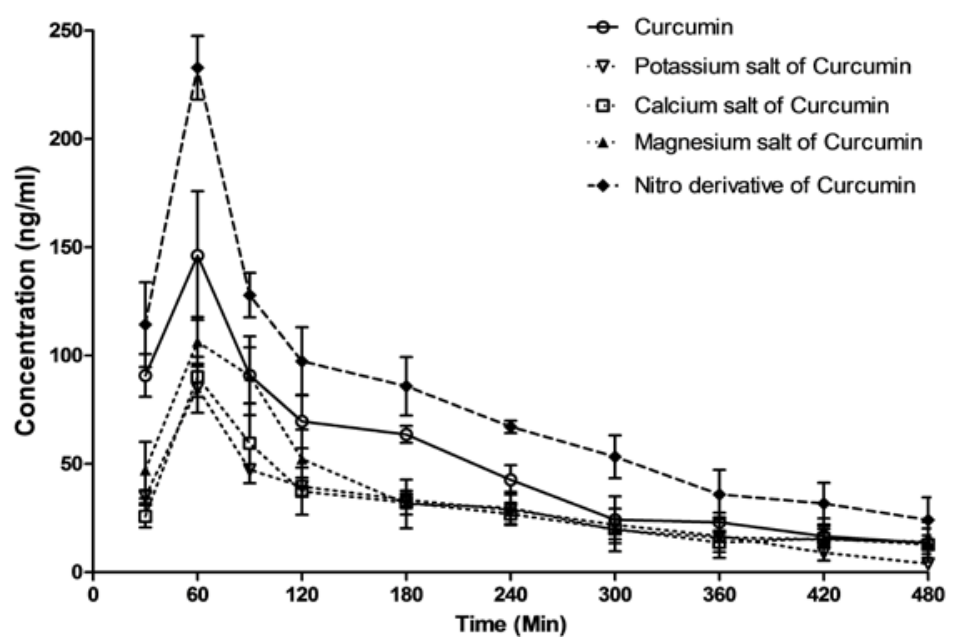

Fig. 4: Plasma concentration time profile of curcumin and its potassium, calcium, magnesium salts and nitro derivative

Curcumin analogues showed greater zones of inhibition than curcumin observed in fig. 3 . Moreover, the in vitro antibacterial efficacy of the curcumin was not affected by the salt and derivative formation, suggesting the intactness of the necessary structural characteristics required for antibacterial activity [25].

As shown in fig. 4 and table 2, the Cmax of curcumin was found to be $148.41 \mathrm{ng} / \mathrm{ml}$. Cmax was increased from $148.41 \mathrm{ng} / \mathrm{ml}$ to $240.17 \mathrm{ng} / \mathrm{ml}$ in case of the nitro derivative. However, in the case of $A U C$, it was increased from 23673.6 to $35971 \mathrm{ng} / \mathrm{mlmin}$. There was no significant difference in the time taken to reach the peak concentration (Tmax) of curcumin and their analogues. No significant result was obtained in case of potassium, magnesium and calcium salt. One of the main reasons for the enhance curcumin oral bioavailability by curcumin analogues is the excellent efficiency of curcumin analogues in improving the drug solubility and in increasing the dissolution rate [26-28].

\section{CONCLUSION}

Curcumin possesses diverse pharmacological activities. Its utility limits due to its poor water solubility, poor bioavailability and rapid metabolism. In consideration to improve aqueous solubility and in vivo bioavailability, structural analogues of curcumin such as potassium, calcium, magnesium salts and nitro derivative were prepared and evaluated. In comparison with curcumin, its analogues exhibited more aqueous solubility. The enhanced solubility data were supported by UV spectral analysis, partition coefficient determination as well as improved cellular uptake by RBC. The analogues were chemically stable as curcumin, which were analyzed by FTIR. The curcumin analogues showed greater antibacterial activity compared with curcumin. The in vivo bioavailability assessment showed that nitro derivative of curcumin illustrated greater C max and AUC than curcumin, suggests improved bioavailability and limits metabolism. The present work recommends that nitration of curcumin improves aqueous solubility which may improve absorption and in vivo bioavailability in rat.

\section{ACKNOWLEDGMENT}

First author is thankful to the Smt. Kishoritai Bhoyar College of Pharmacy, Kamptee, Nagpur for providing assistance to carry out the related research work. The author is also thankful to the Baidhyanath Pvt. Limited, Nagpur for providing curcumin. Authors also thank the Principal Dr. M. J. Umekar, Smt. Kishoritai Bhoyar College of Pharmacy, Kamptee, Nagpur for his undeniable support to carry out the research work.

\section{FUNDING}

Nil

\section{AUTHORS CONTRIBUTIONS}

All the authors have contributed equally.

\section{CONFLICT OF INTERESTS}

The authors declared no conflict of interest.

\section{REFERENCES}

1. Jayadi T, Widiasmoko B. Curcumin benefits as an antioxidant, anti inflammation and antiapoptosis ameliorate paracetamol toxicity. Asian J Pharm Clin Res 2018;15:1.

2. Anand P, Kunnumakkara AB, Newman RA, Aggarwal BB. Bioavailability of curcumin: problems and promises. Mol Pharm 2007;4:807-18.

3. Rai A, Kumar A, Hasan S, Saeed S. Curcumin in oral mucosal lesions: an update. Asian J Pharm Clin Res 2019;12:32-43.

4. Venkatesan N, Punithavathi D, Arumugam V. Curcumin prevents adriamycin nephrotoxicity in rats. Br J Pharmacol 2000;129:231-4.

5. Cheng AL, Hsu CH, Lin JK, Hsu MM, Ho YF, Shen TS, et al. Phase I clinical trial of curcumin, a chemopreventive agent, in patients with high-risk or premalignant lesions. Anticancer Res 2001;21:2895-900.

6. Sharma RA, Euden SA, Platton SL, Cooke DN, Shafayat A, Hewitt HR, et al. Phase I clinical trial of oral curcumin: biomarkers of systemic activity and compliance. Clin Cancer Res 2004;10:6847-54.

7. Itokawa H, Shi Q, Akiyama T, Morris Natschke SL, Lee KH. Recent advances in the investigation of curcuminoids. Chin Med 2008;3:11.

8. Tomren MA, Masson M, Loftsson T, Hjorth Tonnesen H. Studies on curcumin and curcuminoids XXXI. Symmetric and asymmetric curcuminoids: Stability, activity and complexation with cyclodextrin. Int J Pharm 2007;338:27-34.

9. Wahlang B, Pawar YB, Bansal AK. Identification of permeability-related hurdles in oral delivery of curcumin using the caco-2 cell model. Eur J Pharm Biopharm 2011;77:275-82.

10. Weber M, Hunsaker A, Gonzales M, Heynekamp J, Orlando A, Deck L, et al. TPA-induced up-regulation of activator protein-1 can be inhibited or enhanced by analogs of the natural product curcumin. Biochem Pharmacol 2006;72:928-40.

11. Pan M, Huang M, Lin K. Biotransformation of curcumin through reduction and glucuronidation in mice. Drug Metab Dispos 1999;27:486-94.

12. Ireson C, Orr S, Jones J, Versschoyel R, Lim CR, luo L, et al. Characterization of metabolites of the chemo-preservative agent curcumin in human and rat hepatocytes and in rat in vivo, and evaluation of their ability to inhibit phorbol ester includes prostaglandin E2 production. Cancer Res 2001;61:1058-64.

13. Lao CD, Ruffin MT, Normolle D, Heath DD, Murray SI, Bailey JM, et al. Dose escalation of a curcuminoid. BMC Complement Altern Med 2006;6:10.

14. Teiten MH, Eifes S, Dicato M, Diederich M. Curcumin-the paradigm of a multi-target natural compound with applications in cancer prevention and treatment. Toxins 2010;2:128-62. 
15. Mosley A, Liotta C, Snyder P. Highly active anticancer curcumin analogues. Adv Exp Med Biol 2007;59:77-103.

16. Maiti K, Mukherjee K, Gantait A, Saha BP, Mukherjee PK Curcumin-phospholipid complex: preparation, therapeutic evaluation and pharmacokinetic study in rats. Int J Pharm 2007;330:155-63.

17. Shoba G, Joy D, Joseph T, Majeed M, Rajendran R, Srinivas PS. Influence of piperine on the pharmacokinetics of curcumin in animals and human volunteers. Planta Med 1998;64:353-6.

18. Li L, Braiteh FS, Kurzrock R. liposome-encapsulated curcumin: in vitro and in vivo effects on proliferation, apoptosis, signaling, and angiogenesis. Cancer 2005;104:1322-31.

19. Marczylo H, Verschoyle D, Cooke N, Morazzoni P, Steward P, Gescher J. Comparison of systemic availability of curcumin with that of curcumin formulated with phosphatidylcholine. Cancer Chemother Pharmacol 2007;60:171-7.

20. Shaikh J, Ankola D, Beniwal V, Singh D, Kumar N. Nanoparticle encapsulation improves oral bioavailability of curcumin by at least 9-fold when compared to curcumin administered with piperine as absorption enhancer. Eur J Pharm Sci 2009;37:223-30.

21. Yang Y, Lin LC, Tseng Y, Wang C, Tsai H. Oral bioavailability of curcumin in rat and the herbal analysis from curcuma longa by
LC-MS/MS. J Chromatogr B Anal Technol Biomed Life Sci 2007;853:183-9.

22. Brian F, Antony H, Peter S, Austin T. Vogel textbook of practical organic chemistry ( $5^{\text {th }}$ edition); 2012. p. 850-65.

23. Forbes R, York P, Davidson J. Dissolution kinetics and solubilities of p-aminosalicylic acid and its salts. Int J Pharm 1995;126:199-208.

24. Yan Y, Kim A, Kwak K, Yoo K, Yong S, Choi G. Enhanced oral bioavailability of curcumin via a solid lipid-based selfemulsifying drug delivery system using a spray-drying technique. Biol Pharm Bull 2011;34:1179-86.

25. Febriza $A$, Novarina $V$, Idrus $H$, Hatta $M$. The effects of curcumin and vitamin D combination as inhibitor toward salmonella typhi bacteria growth in vivo. Int J Appl Pharm 2019;11:1-5.

26. Hosmani A, Thorat Y. Synthesis and evaluation of nanostructured particles of salt of ketoconazole for solubility enhancement. Dig J Nanomater Bios 2011;3:1411-8.

27. Anand P, Kunnumakkara B, Newman A, Aggarwal B. Bioavailability of curcumin: problems and promises. Mol Pharm 2007; 4:807-18.

28. Burgos Moron E, Calderon Montano M, Salvador J, Robles A, Lopez Lazaro M. The dark side of curcumin. Int J Cancer 2010;126:1771-5. 